liver, which is very tender to the touch and slightly puffed out at the margin of the costal cartilage. He is very restless, and is unable to lie on his right side; and states that he cannot sleep in any position, from the pain in his side. Temperature $103^{\circ}$; pulse 100 , and weak.

On Feb. 1st the fine needle of Dienlafoy's aspirator was inserted below the margin of the costal cartilages two inches from the mesial line, and again between the eighth and ninth ribs in a line below the nipple, but no matter was found. The operation relieved all his symptoms, and he had a good night afterwards, the first he had had for a long time.

Feb. 20d.-As I was convinced of the presence of an abscess, I again inserted the needle in the same spot where the first exploration was made, but more deeply, and drew off a small quantity of pus, which was followed by complete relief. The enlargement of his liver subsided, all pain and tenderness disappeared, and when visited on the following morning, the change which had taken place was most remarkable. $\mathrm{He}_{\theta}$ had slept well during the night, was hungry for his breakfast, had no pain or tenderness in his side, and said be was "all right."

4th.-Tapped in the same hole, and a small quantity of pus drawn off. Temperature $98^{\circ}$; pulse 82 .

5th.-Patient has improved considerably; no pain, no tenderness, no swelling, and he can lie and sleep on either side.

8th. - About an ounce of pus taken from the abscess. Temperature normal.

13th. - About half an ounce of pus taken from the abscess.

18th. - About an ounce of pus drawn off. The wound in the skin is a little inflamed and sore.

As I was leaving Madras, I handed over charge of the patient to Surgeon-Majur Comyn on Feb. 20th, who made the following note in the case-book: "The man is in good spirits and probably improving ; no external discharge."

He left Madras on March 11th, when it was recorded of him: "Has been improving steadily and gaining flesh and strength since last report. He does not perspire at night. Says that he is getting strength daily. No pain in side, but slight heaviness. Wound quite healed; secretions regular. Having been invalided home, he proceeds by rail this day to Deolallee."

I returned to England in the same troop-ship with him. During the voyage he knocked about and ate the usual soldier's rations, and landed at Portsmouth on the 29th of April, fat and well.

Remarks - This case should have been seen to enable one to realise the wonderful change wrought by the operation. When admitted he looked like a dying man, worn out from constant suffering day and night, and in a few days he was restored to comparative health and comfort. The abscess was not found in the first instance, because the needle was not inserted deep enough ; it was in a thin part of the liver, and as the extent of enlargement could not be ascertained in consequence of his side being too tender and painful to admit of it being percussed or manipulated, there was danger of passing the needle right through it. He suffered much from dyspepsia and flatulence, but these symptoms passed off as his side got better.

CASE 12.-Captain H. M. H-, 18th Hussars, aged thirty-eight years; service thirteen years and ten months; Period of residence in India eight years and four months; station Bangalore. I am indebted to Surgeon-major Scott, 18th Hussars, for the following history of this case:"Suffered off and on from sluggishness and general derangement of the liver, associated with hæmorrhoids, since 1869. He visited Madras in 1874, and while there contracted the common continued fever of the country, which lasted only a few days, but left him in a delicate state of health, with some symptoms of hepatic derangement and a return of his hæmorrhoids. About the middle of Junuary, 1875, after his return to Bangalore, he contracted a severe form of remittent fever, which rapidly prostrated his strength; a considerable amount of hepatic derangement, gastric irritation, and bilious diarrhca existed. The remissions were by no means well marked, the exacerbations coming on daily in the afternoon, the temperature then being $1025^{\circ}$ and $101^{\circ}$ during the remission."

The fever was got under sufficiently by large doses of quinine to admit of his removal to Madras on the 5th February, but the liver symptoms were unrelieved, and an abscess formed. On the $6 \mathrm{th}$ of February be arrived in Madras from Bangalore, and I saw him the same day in consultation with Dr. Scott, 18th Hussars, Dr. Colvin Smith, and Dr. Harris, of the Indian Medical Department. Helay in bed in a very prostrate condition and much emaciated; his face was of a peculiar sallow, muddy colour, with an anxious expression of countenance; conjunctiva not jaundiced, tongue deeply furred, dry and brown in the centre, with red tip and edges. Pulse 124, full and compressible; temperature $103^{\circ}$.

The right lobe of his liver was normal, left was much enlarged ; there was a slight bulging just below the ensiform cartilage, and indistinct fiuctuation could be felt; the impulse of the heart's action was plainly felt on placing the hand over the tumour, and it was evident that the abscess was in contact with the pericardium; there was very little pain or tenderness on pressure.

Dr. Colvin Smith explored the abscess with the fine needle of the aspirator, entering it about an inch below the ensiform cartilage, and drew off an ounce and a half of very thick brownish pus. The instrument caused some pain when entering the abscess. The general symptoms were not relieved by the operation. He was so weak that it was not thought advisable to tap the abscess that night; accordingly, the abscess was tapped by Dr. Colvin Smith the following morning, and six ounces of thick pus drawn off. During the operation he became very weak and faint, and was given some brandy.

On the 9 th the abscess was again tapped, and eight ounces of matter, which was perfectly free from smell, taken away. The first seven ounces of matter were much thinner than before; the last ounce was thick and bloody. Inserting the trocar caused a good deal of pain, and he became almost pulseless, but gradually revived. The course of the malarious fever was not influsnced by the operation, and he gradually sank, and died on the 11th February, twenty-six days from the commencement of the fever. No post-mortem examination was obtained.

Remarks.-In this case the abscess was masked by the fever. The latter was so severe from first to last that it is doubtful to what extent the fatal termination of the case was influenced by the hepatic abscess. The patient had the appearance of a man whose system was poisoned with malaria. The cannula could be passed inwards, upwards, and to the left side, for about four inches and a half, when it rested against the pericardium, and the apex of the heart was felt to strike the end of the instrument at each pulsation. The wall of the abscess was doubtless adherent to the pericardium, into which it would probably have pointed had it not been tapped. The danger of using a pen-shaped unsheathed instrument in the above and similar cases is evident.

\section{REMARKS ON RHEUMATIC PURPURA.}

Bx ROBERT LIVEING, M.D., F.R.C.P.,

IATKLY PHYSICIAN TO THF MODDLESEX HOSPITAK, AND PHYSICIAN IN CHARGE OF THE SKIM DEPABTMENT.

RheUmatic pURPuRa, or peliosis rheumatica, is a disease with fairly well defined symptoms. Thus far most observers are agreed, but they hold very different views as to its nature and affinities. By some it is regarded as a form of rhermatism, by others as a kind of purpura, and by a third class as a scorbutic affection. It is really, however, a variety of erythema in which cutaneous hæmorrhages and joint affections are prominent features.

Not long ago two typical examples of this affection came under my care at the Middlesex Hospital : one in the care of a delicate-looking young man, who was admitted into my ward with symptoms of a mild attack of acute rheumatism, but without any serious symptoms. Both ankles were red, swollen, and painful, and on the dorsum of each foot were raised patches of erythema, with large purpuric spots. Numerous spots of purpura without ery thema were present on the legs, and a few small erythematous papules on the 
forearms and backs of the bands. The case ran a somewhat protracted course of several weeks. The knee-joints became affected, and fresh purpuric spots appeared from time to time on the legs aud feet. After some weeks my patient appeared to be quite convalescent; just, however, as be was about to be discnarged be had a relapse, with a recurrence of all the former sy mptoms. The whole attack lasted abont two months. He had had a similar one some years previously. The second case was very similar, but of a milder type.

A very good example of "rheumatism with purpura" is described in Tol. III. of the $L_{\text {ondon Hospital Reports. A }}$ man aged thirty three was admitted under the care of Dr Davies. "Three days before admission be noticed large purple spots appearing on the inside of his ankles and knees; he thught very little of this, however, but applied to be taken in on account of his rheumatism. There had been no bleeding from any mucous membrane. On ad. mission be complained of some pain in bis joints, but the symptoms were not very acute. On the inner side of his ankles, on his insteps, and on his arms, were large purplish blotches." One month after his admission we have the following note:- Th re are no spots anywhere on the skin, and the pain bas quile left the joints;" but ten days later be was "in bed again with a slight return of the rheumatism;" and two duys afterwards we have the following note:- "This evening several raised patches of a purplish colour have appeared about him, which seem to be a mixtnre of the purpuric rash with urticaria. There is very little irritation, and be does not seem to suffer much constitutionally." The "very little irritation" of the spots would seem to correspond with patches of erythema rather than true urticaria. In this case of Dr. Davies there wis sloughing of one of the purpuric spots on the left arm. and also a peculiar effasion into the scrotum and the neigh. bouring tissues. Dr. Perrond, of Lrons, has recorded a similar case, in which a mortification of skin occurred, and also the development of phljetenulæ on some of the pur. puric spots.

As early as 1829 Professor Schönlein described, under the name peliosis rheumatica what he regarded as a new dis ease, characterised by an eruption of purpuric spots accom panied with acute articular pains. Later on, Hebra and others recognised this as a distinct disease, and his de. scription of it corresponds pretty closely with that of Schönlein. He says that the disease begins with dragging pains in the joints, and feverish symptoms, and that when dark-red, livid, or almost black spots appear on the skin, the rbeumatic pains subside. He also mentions tbe fact. that the disease is most frequent between the ages of twenty and thirry, and more common in men than in women. Facbs, and most of the other German writers on this subject, regard the disease as allied to rheumatism, but yet sufficiently distinct to be considered as an independent disease, and distinct from both purpura and erythema. Wunderlich is, however, an exception to the rule, and looks upon the malady as simply a variety of purpura, and the artirular pains as merely an epipbenomenon; while Dr. Buhn, of Konigsherg, regards peliosis rheumatica as identical with erythema nodosum, and conjectures that in both cases the eruption is produced by embolism of the cutaneous capillaries.

The French writers, who have written largely on the subject of peliosis rbeumatica, are almnst unanimous in regarding the disease as a variety of erythema nodosum. In 1858 MM. Legrand and Durian publisbed a monograph on Rneumatismal Peliosis, or Rheumatism which, by an analysis of cases, they claim to show an identity as regards the etiol igy and symptoms of this disease with erythema nodrsam. The peculiarities of the eruption as described by the Germans are regarded by them as hardly sufficient to constitute even a variety of ery thema nodosum; in short, they consider the two diseases as absolutely identical. Baz'n follows on the same side: he says-"Enfin, en Allemagne, le Professeur Subcolein a donné, sous la nom de péliose rbumatismale, l'histoire de l'affection décrite en France sous le nom d'érythème noueux."

In an able paper priblisbed in the American Archives of Dermatology, 1875, Dr. Kinnicutt points ont what he helieves are the differencrs between pelinsis theumatica and simple purpura, and says that the articular pains of the former must not be confounded with the muscular pains of the latter; also that the hæmorrhages in poiosis rbeumatica are all superficial, and do not occur in deep-seated tissues or mucous membranes, as in the graver forms of purpura. As to the identity of peliosis rheumatica with erythema nodosum, be remarks : "Ara we not, therefore, justified in concluding that the only point of resemblance b-tween the eruption of this affection and that of purpura rhenmatica consists in an extravasation of hlood, occurring as we know in various dermatoses, and a certain tendency to recurr nce?" In one disease there is true inflammation, in the other simple hømorrhage. "Aside from the cutanenns aff-ctions, do we find evidence of identity ?" He considers that the absence of arthritic symptoms in mavy cases of erythema nodosum is an important point in favour of the non-identity of the two affections, as such eymptome are pathrgnomonic of peliosis rheumatica, as recognised by the Germans His final conclusions are britfly as folluws:-1. That purpura rheumatica (Schönlein) is identifird by the superficial cha. racter of the eruption accompanied or followed by rheumatic symptoms, and a marked tendency to recurre"ce, the disturbance of the general economy being, in uncomplicated cases, comparatively insignificant. 2. That these cha. racters are sufficient for diffurentiation from different forms of purpura on the one hand and ery hema nodosum on the other. 3. That we are compelled to accord the disease an independent and well-defined position.

Now, no one doubts that arthritic eymptoms are common in ordinary erythema nodosum. Speaking of this distase, S'r T. Watson says: "Rayer bas seen it occur in connerion with acute rheumatiom. So have I. A patient of mine was attacked with acute rhenmatism of the join's immediately upon the cessation of erythema nodosum. In another this order was reversed." Trousseau, in his clinical lectures, remark8: "The articular pains which precede and accom. pany the eruption seem to me to be characteristic of ery thema nodosum." That cataneous hæmorrhage commonly occurs in the swellings of ery thema nodosum is anmitted on all hands, and the fact that tbis affection is very apt to recur is also generally acknowledged. How, then, are we to draw a distinct line between erythema and purpura rheumatica?

Having had several cases of purpura rheumatica under my own care, and having also referred to very many recorded cases, I have been forced to the conclusion that many disinct diseases have been classed under this head simply because they have been attended with cutaneous hoinorrbages and pains in the joints. Purpura is a symptom rather than a disease, and may and does occur in many severe diseases. Now, in order to judge fairly of a disease, it is necessary to examine it in its uncomplicated form; if it only occurs in the course of more serious maladies, it must be regarded as an acoidental complication of those maladies rather than a well-defined disease.

Among the many recorded cases of rheumatic purpura I find a certain small percentage of genuine scurvy, overlooked because the disease occurred under unusual circumstances, and when scurvy was not to be expected. There are also very large numbers of cases recorded under the head of purpura rheumatica where the symptoms have been developed in the course of such grave diseases as advanced phthisis, empyema, kidney disease, pyæmia, morbus cordis, $\&$ c., and I bave myself met with cases of this kind; but in all tbese instances the purpura and pains in the $j$ ints do not constitute a definite disease. Excluding, bowever, all these, there still remains a large number of recorded cases similar to the one $I$ have related above, which are uncomplicated with serious organic changes, and which recover perfectly; these are the cases which cannot, in my opinion, be separated from the symmetrical forms of erythema (erythema nodosum, papulatum, \&c.). The symptoms in all are alike; there is slight constitutional disturbance, articular pains, and sometimes redness and swelling about the joints, with purpuric spots on the skin, either with or without distinct patches of erythema. Usually within a few weeks or months all these symptoms disappear, and the patient is well. Between this not very uncommon affection and symmetrical erythema. I can find no line of demarcation whatsoever.

Since writing the above, I have read with much interest Dr R. Southey's case of purpura rbeumatica in 'The Lancer of July $7 \mathrm{th}$. It belongs, in my opinion, to the class of cases $I$ have pointed out where purpura occurs in the course of some serious malady. There are certain pathological oon- 
ditions common to many diffrent diseases (chronic nephritis is only one of these, heart disease is another) which favour the development of purpura ; but this is not what many of the German and American and all the French writers understand by purpura rheumatica.

\section{ON INCISION OF HYDROCELE ANTI- SEPTICALLY AS A MEANS OF RADICAL CURE IN CERTAIN CASES. ${ }^{1}$}

BY W. H. A. JACOBSON, M.B., F.R.C.S., ASEISTANT-SURGEON TO GUY'S HOSPIMAT.

ON the first occasion of my making use of this method, about a twelvemonth ago, I was not aware that any such operation bad been already performed, but I have found recently that it has been rather largely employed by Prof. Volkmann of Halle'. In this country Mr. Howse has made use of it on one or two occasions.

I propose first to give an account of the operation as made use of by myself, then to speak of its disadvantages and advantages, and finally to mention the cases to which this method would appear to me especially applicable. And before going further $I$ wish to make it quite plain that I do not bring this method forward as one preferable in or. dinary cases to that usually employed-viz., the injection with iodine.

Given, then, a patient with hydrocele, in whom this method is to be employed, the only preliminary required is to shave the pubes and scrotum on the affected side; an incision is then made with the ordinary antiseptic precautions over the upper part of the hydrocele downwards for a distance varying with its size, one of about two inches will usually be sufficient. This incision should go at once down to the tunica vaginalis, which is nearly always thickened, and readily recognised. A corresponding incision is then made through the tunica raginalis, and this should be done quickly; otherwise, as the long-stretched dartos rapidly contracts, the resulting aperture will be found too small for the satisfactory carrying out of the next step. This consists in tucking in a narrow strip of gauze soaked in carbolic oil. The object of this is to ensure that granulations shall spring up all over the opened sac so as to procure its obliteration. The usual antiseptic dressings are then applied, overlapping the wound carefully in every direction, perforated for the passage of the penis, and kept in position by a double spica bandage. The wound should be dressed once in the two following days, after this every second, third, or fourth day. All that is required is to syringe out the wound with a solution of carbolic acid ( 1 in 40), and on the first one or two occasions to reinsert a fresh strip of oiled gauze. Four or five days after the operation the patient may get up, and at the end of a fortnight he may leave the hospital. If the wound has not completely healed by this time all that will be left will be a small granulating surface, and the only treatment needed is to reapply every other day a bit of boracic lint, and to keep the testicle suspended a little longer.

To proceed with the disadvantages of the operation:-

1. It involves more trouble undoubtedly than the treatment by injection. 'The operation itself may be completed in ten minutes, but an anæsthetic will generally be required, and there is the trouble of the subsequent dressings.

2. Another objection may be raised that this method must require a much longer time than that of injection. To a certain extent only is this objection a valid one. The five cases which I treated in this way had an average duration of treatment of just over three weeks. I find, from

1 Abstract of a paper read before the Hunterian Society, April 11th, 1877. 2 Berlin Klinische Wochenschrif , No. 3, 1876 ; Med. Record, April, 1876; Dentsche Zuitschrif. für Chirargie, July, $18 \% 6$.

Pro?. Volkmann, I find, on the other hand, endearonrs to keep the surfaces of the incised tunica raginalis in apposition, and so as to insure their
adhesion. an analysis of forty-three cases in which iodine was injected, the average duration of treatment, or rather of their stay in the bospital, was quite fifteen days. But, as bearing upon this question of time, I find frequently at the end of the reports of these cases of patients who, after injection, left the hospital at the end of the second week, some such note as, "Scrotum as large as before, but painless," "Scrotum still twice natural size," \&c. It is obvious there. fore that a patient cannot do much work in this condition. Mr. Curling ${ }^{4}$ says, speaking of the cure by injection of iodine, "in about three weeks the cure is usually accomplished." If therefore three weeks and a few days be allowed as the time required for the accomplishing of the cure after the antiseptic incision, the difference is but slight.

3. It may be objected that such an operation as the one described above is severe, and involves risk. In answer to this $i$, is only fair to remember that incising the tunica vaginalis with antiseptic precautions is totally different from the operation of incision as carried out a hundred years ago. For instance, Samuel Sharp (one of the eariiest surgeons at Guy's Hospital) describes four cases treated by the old method of incision in bis Treatise on the Op rations of Surgery (published 1739). From the severe "symptomatick" or traumatic fever, and the smart secondary bæmor. rhage from the vessels of the inflamed scrotum, the suppuration and sloughing, he speaks of these cases as sta catalogue of misfortunes," and of himself as having been threatened with the death of his patients, though none actually died. Contrast this with the cases operated on by the antiseptic incision, the temperature in not one of them rising at any time higher than $998^{\circ}$, and that only in the thirty-six hours following the operation, then at once falling to normal, and remaining so throughout the rest of the treatment; any constitutional disturbance present during the first twenty-four hours being of the most trivial kind, and afterwards entirely absent.

I have spoken separately of the disadvantages of this method. In bringing this paper to an end I will consider together the advantages of the method and the cases to which it would appear to me to be especially applicable.

(a) It is absolutely certain, for the cavity of the tunica vaginalis is obliterated by granulations. On account of this advantage I should be inclined to use this methnd where attempts at a radical cure by injection with iodine have already failed. I quite admit that this is rare, but it undoubtedly does occur. Out of forty-four cases of which I. have notes, the injection with iodine failed in eight, and in two of these it failed twice. I may add that these cases were under the care of the surgeons and assistant-surgeons at Guy's Hospital, and that in some cases the injection used was of the ordinary strength, equal parts of water and the tincture; in others the undiluted tincture. I would also make use of this method, not only where injection has already failed, but also where there is a risk of its failingi.e., where the sac has very thickened walls, or where the hydrocele is very large in size; for here, tno, the injection by iodine may fail, partly because all the fluid may not be removed by tapping, and also on account of the difficulty of bringing the iodine injected thoroughly in contact with the inner surface of the tunica vaginalis.

(b) This method may be safely employed in cases where a radical cure is desired, but where from ill-health or age injection with iodine may be thought to be contra-indicated. Thus one of the cases in which I used it was that of a dis. sipated London tavern-waiter much let down in health, and having a crop of boils about him, and a small carbuncle on his neck. The man was about fifty, and the bydrocele a large one, which had been tapped ten times. In this case I should not have liked to have employed the iodine injection, but I had no hesitation in employing the antiseptic incision, and the man was relieved of his troubles at one and the same time, for, while the tunica vaginalis was filling up, his neck healed.

(c) In some cases of congenital hydrocele which have re sisted milder means, I believe that a careful incision, with antiseptic precautions, will obliterate the communication with the peritoneal cavity quite as safely and far more surely than the pressure of a truss, which is usually recommended to be perseveringly applied. [Sine this paper was read, a

\footnotetext{
4 Diseases of the T stic, hind Edition, p, 13:,
} 